\title{
$O$ professor e a leitura: questões de formação
}

\author{
Angela B. Kleiman \\ "...oprazer da leitura é um prazer aprendido" \\ Marisa Lajolo. Meus alunos não gostam de ler... o que eu faço?
}

À Marisa, que acredita na formação do leitor

\section{Leitura e posicionamento identitário}

Os estudos sociointeracionistas preocupados com a formação do leitor - em geral no contexto da escola - destacam o papel central da interação na formação de leitores. Esses estudos pressupõem que o contexto de situação é construído: resultante de movimentos ou orientações locais, pontuais, realizadas passo-a-passo pelos participantes da interação, em função de seus propósitos e intenções individuais, das relações que têm com o outro, das representações da situação, incluindo-se aí a concepção de leitura e do gênero que permite participar das situações. ${ }^{1}$

Nessas pesquisas, enfatiza-se o alcance das ações do professor no contexto da aula, uma vez que seu papel é determinante na construção de relações (confiança, segurança, respeito, diferenças e simetrizações baseadas no status, no poder, no sexo ou na etnia, entre outros), de identidades (bom ou mau aluno, leitor fraco ou forte, etc.) e de ambientes que colaboram para inibir ou favorecer o sucesso ou o fracasso na aprendizagem. Em relação à formação de leitores, temos que as normas sob as quais professor e alunos desempenham seus papéis na complexa trama interacional tecida na aula ${ }^{2}$ poderiam, em princípio, ser subvertidas, enfatizadas, negociadas ou impostas. Entretanto, embora a escola enuncie, nas palavras de Hébrard, ${ }^{3}$ as normas legítimas do uso dos "equipamentos intelectuais de uma sociedade", é fato que na sociedade brasileira os cânones escolares de leitura constituem apenas revozeamentos de normas e cânones produzidos por grupos que em geral estão longe da escola, tais como os grupos acadêmicos.

Um objeto bem menos estudado, mas também determinante na cadeia de processos envolvidos na formação de leitores, é o alcance das ações do professor-formador (na esfera acadêmica), nas aulas daqueles que ensinam a $\operatorname{ler}^{4}$ (e a escrever). Esse é objeto da pesquisa desenvolvida desde $2003{ }^{5}$ por um grupo de pesquisadores de seis instituições do país ${ }^{6}$, que investigam a constituição identitária dos formadores de leitores: alfabetizadores e professores de cursos de Letras e Pedagogia em formação inicial e continuada; educadoras populares e outros agentes sociais comunitários que promovem os usos da escrita, por exemplo, de jovens negros pertencentes ao movimento hip-hop. A pesquisa tem como um de seus objetivos precípuos desviar o olhar das práticas escolares - uma forma de pesquisa que acaba, muitas vezes, por responsabilizar o professor pelo fracasso escolar - e dirigi-lo para as práticas de letramento do curso superior, a fim de 
investigar, nas interações que se realizam nessa esfera, os gêneros formadores e outros acervos de leitura, os modos de lê-los e as representações sobre a leitura que são aí construídas e negociadas ${ }^{7}$.

Uma preocupação fundamental dos pesquisadores é a de evitar que os resultados da pesquisa contribuam para reforçar posicionamentos sociais e relacionais que enfatizam diferenças e hierarquizações baseadas em desigualdades de poder e de status entre o aluno e o professor e seus críticos. Como em toda interação institucional, nas interações acadêmicas, os indivíduos cuja formação estudamos - devemos lembrar, muitos deles de baixa extração social e de pertencimento e trânsito periférico nos circuitos culturais reconhecidos e valorizados pela academia - podem se posicionar, e ser posicionados, subalternamente, conformando-se ou submetendo-se às práticas de leitura e às representações sobre a leitura legítima dos grupos dominantes, ou podem se posicionar como sujeitos que atuam autonomamente e que resistem às hierarquizações, a fim de causar transformação numa dimensão social ou coletiva. ${ }^{8}$

A transformação é necessária para formar um professor mais próximo do perfil que a sociedade parece desejar, mas que parece estar - a julgar por certas ações que serão discutidas a seguir - na contramão do que ela acredita serem as competências necessárias para um profissional desse perfil. As representações sobre o professor ${ }^{9}$ o descrevem como não-leitor, com falhas e limitações tais no seu manejo da língua escrita que não apenas sua capacidade de ensinar a ler e escrever estaria comprometida; de fato, questiona-se a sua própria capacidade de leitura e escrita ${ }^{10}$, como veremos nos dois exemplos a seguir.

\section{Dois exemplos}

Se considerarmos certas ações de órgãos e agências governamentais, como as secretarias de ensino e as instituições de pesquisa do MEC, a representação do perfil de leitor do professor parece implicar a aceitação de um profissional já carente de capacidades básicas, essenciais até, de leitura. A análise de provas e exames que avaliam os conhecimentos e capacidades desse profissional em distintos momentos de sua aprendizagem e formação, ao término da formação inicial (i.e., no antigo Provão) ou em concursos públicos, mostra a adoção dessa premissa: essas provas não mais operam com uma representação do professor como pertencendo aos grupos que sabem ler textos com compreensão adequada; pelo contrário, parecem operar com o pressuposto de que, na hora de contratar ou avaliar para ensinar os alunos da comunidade a ler, há o risco real não de acabar dando o emprego a pessoas que não conseguem ler como um professor isto é, que não conseguem transformar as leituras em atividades didáticas - mas a indivíduos que sequer entendem um texto simples em prosa ${ }^{11}$.

Somente esse pressuposto explicaria uma estratégia comum em provas para provimento de cargo de professor que consiste em solicitar ao candidato que leia um texto e que responda a questões objetivas, de busca de informação, sobre ele. No exemplo a seguir, reproduzimos parcialmente uma das perguntas de um teste de concurso para a função de professor alfabetizador, formulado por uma secretaria de Ensino de um pe- 
queno município da região sudeste. O item transcrito - uma das perguntas e parte do trecho ao qual a pergunta se refere - tenta verificar se o professor consegue entender as informações veiculadas num pequeno texto em prosa retirado de uma reportagem publicada na revista Veja:

(...) Essa e outras ilhas se salvaram da predação urbana graças à geografia íngreme, o que arremata esses cenários com cachoeiras de tirar o fôlego. (...)

Questão 03:

Muitas ilhas se salvaram da destruição ambiental porque

A) o interesse dos turistas é muito grande

B) o acesso às suas matas é muito difícil

C) as suas quedas d'água são muito altas

D) a sua fauna e flora já foram depredadas

A questão no exemplo não tem por objetivo verificar se o candidato sabe como ensinar seus alunos a ler textos de uma revista de notícias (por exemplo, se ele sabe fazer perguntas para facilitar o entendimento dos alunos, para seus alunos acharem esse tipo de informação), mas se ele próprio consegue extrair informações e compreender uma paráfrase desse tipo de texto. Portanto, visa-se à verificação da capacidade de compreender a informação veiculada em reportagens de revistas noticiosas semanais, um gênero corriqueiro, com textos altamente previsíveis (quanto ao estilo, conteúdo e estrutura), cuja leitura não exige muita reflexão ou conhecimentos. A habilidade de compreensão testada é uma das habilidades básicas da capacidade de leitura, da qual outras habilidades e estratégias - inferenciais, avaliativas, críticas - dependem.

O segundo exemplo, também de avaliação, ilustra o efeito dessa contínua desvalorização na representação que o professor faz de si mesmo. Em trabalho recente sobre o desempenho de formandos de cursos de Letras de faculdades e universidades da cidade de São Paulo no Provão de 2001, Castro ${ }^{12}$ analisa as respostas de 290 formandos a uma das perguntas da prova, a qual fornecia uma redação que uma menina de dez anos teria escrito, seguida do seguinte enunciado:

\footnotetext{
"Uma característica desse texto é a forma como a menina faz as ligações coesivas. Elabore um texto no qual você proponha alterações para o segundo parágrafo, apresentando soluções para o problema dos elos coesivos. Justifique as alterações sugeridas com o apoio de noções lingüísticas."
}

As respostas dos formandos foram variadas em grau e número quanto aos tipos e adequação das intervenções. São interessantes para nós os 51 alunos, 17\% dos formandos cujas provas foram analisadas por Castro, que não propuseram nenhuma intervenção e que entenderam que o enunciado pedia que elaborassem um texto tal qual o da menina e assim o fizeram (completando o da menina ou fazendo um outro sobre o mesmo assunto, uma família de férias), como se eles, professores de Língua Portuguesa recém-formados, tivessem de demonstrar a própria capacidade de escrever uma redação escolar sobre o mesmo tema da redação em análise. Além do óbvio problema de compreensão do enun- 
ciado (interpretação com base em informações parciais), tal desempenho revela uma auto-estima tão baixa desse grupo em relação a suas capacidades de uso da língua escrita que não o deixa perceber a inadequação de tal comprovação, tratando-se de um profissional encarregado do ensino e avaliação de textos como aquele que produziu para a prova.

Os dois exemplos ilustram como têm sido rebaixadas as expectativas da sociedade em relação aos egressos dos cursos de Pedagogia e de Letras e, conseqüentemente, como têm sido empobrecidas as (auto)representações desse professor. Uma sociedade que sequer espera que o professor saiba ler e um professor que, além de não compreender pequenos enunciados, acredita que, numa situação de exame, tem de demonstrar que sabe completar uma redação escolar, não auguram os bons resultados na formação de leitores que essa mesma sociedade, incoerentemente, espera desse profissional.

O trabalho de formação de leitores vai além da compreensão do texto. A leitura, assim como os demais usos da escrita, é constitutiva do "ser professor" e, portanto, o seu letramento deve ser entendido como uma construção identitária. Isso significa que a capacidade de ler não só com compreensão, mas também analiticamente, identifica o professor como profissional encarregado da inserção de outros nas culturas letradas. Nesse entendimento é que poderemos começar a repensar as atividades e os programas a que submetemos os alunos que no futuro ensinarão a ler e a escrever. A nossa pesquisa, que passamos a descrever sucintamente, visa à descrição acurada dessa dimensão identitária do (aluno) professor e à investigação de estratégias que possam reverter o fracasso das instituições de ensino superior na formação desse profissional.

\section{A pesquisa sobre a formação do professor}

O Grupo Letramento do Professor defende a idéia de que o trabalho do alfabetizador e do professor de língua materna estaria mais bem representado através da imagem do agente social, o agente de letramento. O conceito vai além da idéia de agência humana, pois essa é própria de todos os seres humanos: todos nós somos agentes à medida que atuamos e modificamos nosso mundo. Refere-se ao agente social, ${ }^{13}$ capaz de articular interesses partilhados, de organizar um grupo ou comunidade para a ação coletiva, de auxiliar na tomada de decisões sobre determinados cursos de ação, de interagir com outros agentes de forma estratégica e de modificar e transformar seus planos de ação segundo as necessidades em construção do grupo. ${ }^{14}$ Trata-se de uma representação não compatível com as das agências governamentais e com a do próprio professor, discutidas na seção anterior.

Essa representação de agente de letramento configura um conjunto diferente de exigências para o exercício da profissão: a familiaridade com múltiplas práticas de letramento é ainda essencial, mas tão importante quanto isso é a capacidade de mobilização da comunidade de leitores (em formação) com vistas a um objetivo em comum. Essa capacidade tem a ver com a autoconfiança, com a imagem positiva, com a assertividade ${ }^{15}$,

pois são tais características que subjazem ao desenvolvimento de competências discursivas 
necessárias para interessar outros na leitura, como a capacidade de analisar uma situação e a de buscar soluções para os problemas com base no conhecimento do grupo atendido.

A formação desses agentes coloca outras obrigações para os seus formadores: não é admissível lamentar que os alunos que chegam ao curso de Letras e de Pedagogia venham desprovidos de práticas de letramento de prestígio; tal lamúria é semelhante, por exemplo, à do professor que sente saudades dos dias em que todos os alunos chegavam à escola já letrados, precisando ser apenas alfabetizados. Se um agente de saúde não conseguisse convencer as mulheres de uma aldeia da necessidade de ferver a água que bebem para evitar as doenças e ficasse apenas lamentando os hábitos do grupo e desejando que elas fossem mais cooperativas ou mais receptivas, esse agente de saúde não iria longe no seu trabalho. Algo diferente ocorreria ao agente que, por exemplo, descobrisse que essas mulheres têm um acervo de tradições nas quais acreditam e que usasse esse conhecimento, transformando o saber científico numa nova 'simpatia', tal como: a água não é só fervida, mas 'fervida em jejum, mexida três vezes, repousada a manhã toda e só depois decantada e bebida pelo bebê'. Esse agente teria chances de atingir seu objetivo de transformar práticas tradicionais em descompasso com as necessidades da vida moderna. É isso o que se espera do professor como agente de letramento e é isso que se espera do formador de professores quando o objetivo é formar agentes de letramento.

Trazer à cena os saberes de senso comum, não-científicos, tradicionais ou populares do estudante-futuro-professor está longe de simplificar ou popularizar o processo de formação pela relativização dos saberes. Uma avaliação realista do letramento do estudante e da desigual valoração e legitimidade dos saberes ${ }^{16}$ é uma etapa necessária para mudar a situação, tomando as informações dessa avaliação como ponto de partida, nunca de chegada, do processo de formação profissional. Assim, se interessa à sociedade formar um profissional que tenha um gosto literário desenvolvido, a leitura dos cânones é essencial, mas ela pode ser objetivo, não meio, para desencadear esse processo. Incluir no programa a leitura de livros clássicos sem ter certeza de que o aluno os entende é um fazer de conta que em nada se diferencia das práticas a que já foi submetido e que não desenvolveram nele, na sua escolarização pregressa, nem o gosto pela literatura nem, muitas vezes, e cada vez com mais freqüência, a capacidade de ler.

Visando à proposição de estratégias e até a programas ${ }^{17}$ para os alunos que hoje freqüentam faculdades e universidades, o Grupo Letramento do Professor pesquisa diversos instrumentos, assim como diversos modelos de formação, que podem vir a favorecer o letramento do professor para o seu trabalho, não como mero instrumento para realização do trabalho, mas como aspecto constitutivo, identitário de sua função como formador de novos leitores.

\section{Os estudos sobre posicionamentos identitários}

Um conjunto de pesquisas tem por objetivo o desvendamento das ideologias que posicionam os indivíduos como sujeitos menores, em função de sua extração social e precária escolarização formal. Esse processo de desnaturalização da ideologia é entendi- 
do como um dos elementos-chave para a transformação e a resistência desses grupos. ${ }^{18}$ Por meio da comparação das auto-avaliações do professor alfabetizador, como leitor, com as auto-avaliações de outros agentes de letramento, por exemplo as alfabetizadoras populares, é possível contrapor aspectos do modelo de formação acadêmico com outros modelos de formação profissional e compará-los quanto aos elementos que neles colaboram para favorecer ou inibir uma valoração positiva das próprias capacidades como leitor. Os dados de Vóvio ${ }^{19}$ sobre os discursos de alfabetizadoras populares em rodas de leitura que se auto-definem como leitoras (eu sou uma leitora crítica, curiosa, exigente) e que descrevem, com entusiasmo e segurança, os mundos de leitura pelos quais transitam mostram que, nos posicionamentos sociais dessas alfabetizadoras, com pouca educação formal, não há reconhecimento submisso da cultura dominante. Essas alfabetizadoras se auto-posicionam como leitoras e constroem histórias de leitura nas quais elas são protagonistas, ao mesmo tempo que usam estratégias de fortalecimento mútuo que favorecem o fortalecimento do grupo. ${ }^{20}$

Por outro lado, os dados de entrevistas com professoras alfabetizadoras em curso de formação em universidade pública de elite, com tradição de pesquisa, mostram que as professoras não se representam a si mesmas como leitoras, como membros legítimos dos grupos letrados que representam na escola (eu não leio, não consegui terminar o livro, não tenho o tempo para ler que en gostaria de ter); nos seus discursos muitas delas se posicionam subalternamente, em relação aos seus professores universitários e às demandas acadêmicas que lhes são feitas. Há duas atitudes distintas em relação à leitura de segmentos dominados: contraposição à hierarquia, baseada na valorização da cultura popular e do grupo a que pertencem, próprio dos agentes comunitários, por um lado, ou reconhecimento submisso da superioridade da cultura dominante e o esforço sistemático e disciplinado para adquirir educação formal (ainda inédita na família), mais comum nos grupos em ascensão, por outro. Sendo assim, podemos distinguir duas dimensões identitárias dos agentes de letramento e sugerir dois modelos de letramento, aquele dos graduados do ensino superior, que pode diminuir a confiança dos indivíduos, e aquele dos agentes comunitários, que pode fortalecê-los. ${ }^{21}$

\section{A construção do conhecimento na interação: conceitos e representações sociais}

Outro enfoque da pesquisa são os modos como professores organizam conhecimentos relativos a seus objetos de ensino (por exemplo, em relação à textualidade, o que é texto, o que é coerência). Esses estudos analisam as categorias e conceitos mobilizados por alunos e professores para tornar familiar o conhecimento de cunho científico das disciplinas de formação. São de especial interesse a construção e organização de saberes teóricos por professores afastados dos grandes centros de produção do saber, ${ }^{22}$ pois a pesquisa permite conhecer crenças, valores, opiniões, modos de dizer locais que apontam para modos de recortar o mundo e de trazer à cena as representações sobre objetos de trabalho e de estudo que não podem ser levadas em conta em textos formadores 
dirigidos a um público nacional e que são em geral desconsideradas pelos formadores universitários.

Esses trabalhos mostram que a atividade de ensinar é social e que construir conhecimentos não é um processo exclusivamente cognitivo, pois, nele há histórias e momentos de subjetividade, que, muitas vezes, são desconsiderados pela instituição formadora. Tal enfoque permite entender as categorias que os professores usam, não como uma ruptura radical dos conceitos ensinados nos textos do discurso científico e de divulgação científica na formação, mas como um processo de familiarização e de metaforização das categorias científicas a partir de categorias locais. Os dados são necessários para reparar a quebra do diálogo entre o acadêmico e o professor em formação, que pode também decorrer do desconhecimento por parte do formador universitário desses sistemas de conhecimentos (teorias sobre o mundo, segundo Gee ${ }^{23}$ ) com categorias cuja estrutura nos remete a representações sociais de senso comum ${ }^{24}$ muito mais do que a categorias científicas. ${ }^{25} \mathrm{Um}$ outro subconjunto interessante examina as metáforas conceituais (o texto é um quebra-cabeça versus o texto é um produto de trabalho) subjacentes no discurso do professor e do acadêmico, respectivamente, em interações. ${ }^{26}$

\section{Processos, modelos e gêneros de formação}

O terceiro conjunto de trabalhos do grupo envolve, de modo geral, a análise de processos, propostas e gêneros de formação.

A análise dos processos de retextualização ${ }^{27}$ envolvidos nos exercícios de formação que demandam a leitura de um ou mais textos na área e a produção de um novo texto com base nessas leituras - como uma resenha, um resumo, um projeto - permite entender os processos de inserção do professor nas práticas acadêmicas de leitura (e produção de textos). ${ }^{28}$ Esses trabalhos examinam as relações imbricadas entre os discursos sobre a linguagem em diversas esferas de ação, como a acadêmico-científica, a de divulgação e a escolar e, ao focalizar a construção dos saberes nas práticas de formação profissional, fornecem informações sobre as filiações ideológico-culturais dos alunos (daí sua proximidade com os trabalhos sobre as representações sociais dos alunos) ${ }^{29}$; sobre os modos como eles mobilizam saberes na leitura e na produção dos textos emergentes desse exercício de formação e sobre o funcionamento dos gêneros nessas práticas. Ao mesmo tempo, a retextualização, enquanto exercício pedagógico de formação que envolve o registro das leituras de sua área e promove a compreensão conceitual, permite que o aluno tenha acesso aos modos de textualizar os saberes e que se aproprie de conceitos e procedimentos acadêmico-científicos (o gerenciamento de vozes, referenciação, por exemplo), todos eles concebidos pelos pesquisadores como processos essenciais para a formação profissional.

Em relação aos gêneros de formação, há investigações que procuram entender melhor os dispositivos tradicionais da aula, como o uso do livro didático, assim como há investigações sobre propostas de gêneros e práticas que inovam, como o memorial, o diário de aprendizagem e o projeto de letramento. Os estudos focalizando esses objetos 
problematizam as concepções do professor (por exemplo, a do professor de Língua Portuguesa como um "consumidor passivo" e, portanto, um leitor passivo, do livro didáti$\mathrm{Co}^{30}$ ); porém o objetivo principal é a proposição e análise de gêneros formadores que possam ser objetos de recontextualização e de ressignificação em novas situações de comunicação. As nossas atividades são realizadas no mundo social, em situações concretas que estão determinadas pelas instituições, mas que também oferecem espaços para mudanças no cotidiano das relações; uma possível esfera de transformação está nos gêneros, se a sala de aula for entendida como espaço de experimentação de práticas sociais, às quais se tem acesso via leitura (e produção) de textos de diversos gêneros.

Uma abordagem importante na experimentação com gêneros de formação, com vários pesquisadores envolvidos, consiste em recuperar, por meio da rememoração e do registro, as histórias de leitura pessoais e profissionais. Um grupo de pesquisadores, ${ }^{31}$ utilizando a metodologia da História Oral ${ }^{32}$ analisa a memória como alternativa (o que poderia ter acontecido) e, nesse sentido, ela pode ser interpretada como uma forma de resistência; assim, o esquecimento e os silêncios de um grupo social ou de um indivíduo nem sempre são sinônimos de passividade ou conformismo, mas podem ser formas de resistência às memórias dominantes em dada sociedade em um determinado tempo histórico.

O método colabora para relativizar os saberes e perspectivas considerados legítimos, à medida que favorece o processo de rememoração do pesquisador também. Assim, fica evidente que pesquisador e pesquisado exercem influências um sobre o outro e o entendimento de suas respectivas histórias cria condições de entender versões não legitimadas, em contraponto às interpretações acadêmicas.

Para investigadores que pesquisam os gêneros que envolvem o exercício da memória, o processo de reconstitutição de uma história pessoal da professora envolve também a reconstituição do contexto sócio-histórico da época da alfabetização, da escola, da rede de ensino, as condições de trabalho no magistério, o papel da escola, as concepções de leitura, que se articulam com a noção de identidade, de construção de si. Entender as escolhas narrativas de cada indivíduo entrevistado envolve considerar o contexto histórico em que se dá o depoimento, compreendido como um 'fazer textual' indissociável desse contexto. As memórias narradas, as biografias, os memoriais apresentam-se como versões de suas trajetórias de leitura e como possibilidades de interpretação do passado. ${ }^{33}$

O diário de aprendizagem é um gênero com múltiplas possibilidades de registro. No contexto da pesquisa do grupo ${ }^{34}$, ele propiciou o registro de impressões, recordações, sentimentos relativos à atividade de ler (e de escrever), a fim de tornar o processo de aprendizagem objeto de reflexão do aluno, futuro professor de Língua Portuguesa. O objetivo do estudo desse gênero é o de analisar evidências de uma construção identitária profissional a partir de registros subjetivos sobre práticas e eventos de letramento em sala de aula, orientados por perguntas metaprocedimentais, que o levam à conscientização dos processos envolvidos no ensino e na aprendizagem. A análise longitudinal da produção nos diários evidencia que o diário funciona como um instrumento para a emergência, ordenação e organização das representações sobre o ser professor, provavelmente em decorrência do distanciamento viabilizado pela escrita sobre a vivência acadêmica. Os 
pesquisadores desse instrumento afirmam que é no registro propriamente dito que acontece o processo de construção identitária, ao mobilizar a atenção dos alunos para seus próprios processos de aprendizagem na construção da vida profissional. Tal constatação constitui justificativa importante para a pesquisa de estratégias de uso do gênero em outras esferas da vida social, como a escolar.

O projeto de letramento é entendido como uma prática que pode ser recontextualizada pelas atuais demandas sociais e que favorece a participação e os reposicionamentos identitários do aluno, em decorrência do tipo de prática de uso da língua escrita que promove, em função de finalidades que vão além das escolares, de ler e escrever para aprender a língua escrita. ${ }^{35}$ No contexto da pesquisa do grupo, o projeto é entendido como um conjunto de atividades que se origina de um interesse real na vida dos alunos e cuja realização envolve a leitura de textos que, de fato, circulam na sociedade e a produção de textos que serão lidos, em um trabalho coletivo de alunos e professor, cada um segundo sua capacidade na tentativa de compreensão e resolução de um problema de interesse das comunidades de aprendizagem ${ }^{36}$, com objetivos comuns, provisoriamente constituídas para desenvolver o projeto. ${ }^{37}$

Os projetos estão articulados em torno de um tema, o que os torna mais próximos de práticas seculares da escola, e são viabilizados pela mobilização de gêneros que permitem a participação na vida social, o que os aproxima de novos parâmetros do ensino, mas nem tema (conteúdos) nem gênero são os elementos que definem as ações didáticopedagógicas: é a prática social, tal como a leitura que viabilizará a participação em um concurso sobre a escrita ou a elaboração de um jornal de escola; ou aquela necessária para manifestar-se e ser ouvido sobre alguma questão polêmica de interesse local ou nacional, ou para tentar salvar um animal do zoológico da cidade, ou ainda, para satisfazer a simples curiosidade sobre a borboleta. A constituição de modelos didáticos que incorporam princípios da pedagogia de projetos e dos estudos do letramento constitui outra vertente de pesquisa, nos estudos de Tinoco. ${ }^{38}$

Em geral, diversas comunidades de aprendizagem que promovem a leitura de seus membros, como as redes profissionais de formação, em Farinha, ${ }^{39}$ os cursos de formação inicial ou continuada oferecidos pela equipe, ${ }^{40}$ formam objetos de estudo privilegiados pelos pesquisadores do grupo, que procuram entender quando e por que essas comunidades, com suas múltiplas abordagens das práticas letradas, modos de ler e diversas formas de circulação dos equipamentos culturais fazem a diferença e formam (ou reformam) leitores.

\section{Considerações finais}

Se a leitura, como toda prática de letramento, é uma atividade situada, determinada pelas dimensões sócio-históricas do uso da língua escrita, então, leituras, acervos e modos de ler estarão circunscritos e determinados pelas histórias de vida do leitor. $\mathrm{O}$ desajuste entre as expectativas da sociedade com relação ao perfil do professor e a familiaridade efetiva desse profissional com práticas de letramento legitimadas não poderia 
ser diferente se consideramos que, em função da extração social do alfabetizador e do professor de língua materna, a maioria adquiriu suas práticas de uso da língua escrita em escolas públicas e faculdades de menor prestígio que não chegam a constituírem-se em contextos capazes de re-configurar as experiências iniciais de leitura desses profissionais. Uma análise realista dessa situação não implica a sua aceitação; pelo contrário, cabe uma reação vigorosa dos seus formadores no sentido de adequar as práticas acadêmicas a fim de formar sujeitos seguros na sua familiaridade com os textos e as práticas de leitura de diversas esferas de atividade bem como a mobilização dos alunos em prol de um objetivo comum cuja realização envolve ler e escrever em situações sociais que requerem tanto o uso de conhecimentos e de práticas já adquiridos como a contínua aprendizagem de novos conhecimentos e práticas.

Chamamos o profissional com esse perfil de agente de letramento. Há vantagens estratégico-políticas nessa forma de conceitualizar o trabalho do professor. O conceito de agente de letramento aponta para um novo conjunto de comportamentos, habilidades e competências necessários para realizar as complexas atividades de ensinar a ler e escrever, de formar o gosto pela leitura e de formar novos leitores hoje. O professor precisa se dedicar mais às ações sociais mediadas pela leitura para assim, desenvolver saberes e competências, e se preocupar menos com conhecimentos prontos e acabados, com o domínio de conteúdos; em outras palavras, precisa liderar com segurança o planejamento, organização e realização de atividades envolvendo o uso da escrita que interessem o aluno e que tenham alguma função real na sua vida social. Essa representação pode também potencializar o fortalecimento do professor - um dos elos mais fracos na cadeia de responsabilidades (só o aluno está abaixo dele) - que, há algumas décadas, é responsabilizado pelo fracasso do ensino, por diversas instituições formadoras de opinião (governamentais, acadêmicas, jornalísticas).

Acreditamos que cabe à academia, em última instância responsável pela formação de professores, reposicionar-se no debate sobre o letramento do professor, a fim de assumir uma voz discordante da mídia e das agências governamentais quando estas divulgam simplesmente que ele não lê ou que é mau leitor. Com esse objetivo, investigamos, há quatro anos, as práticas de leitura e de produção textual desse grupo profissional a partir de uma perspectiva identitária, não instrumental, dos usos da língua escrita. Essa perspectiva recusa o retrato genérico do professor como o de um indivíduo que não sabe ler e, por meio de metodologias qualitativas, investiga as suas práticas de letramento nas esferas de atuação profissional. Nessa perspectiva não interessam avaliações genéricas sobre as capacidades neutras, descontextualizadas, autônomas da situação social: interessa saber como esse profissional escolhe um material didático, a quem recorre quando precisa escrever um texto num gênero não familiar, o que gosta de ler e o que consegue ler analiticamente, para fins didáticos. Nessa perspectiva crítica, a pesquisa é conceitualizada como oportunidade para desenvolver propostas, modelos e gêneros de formação do professor que possam vir a ser usados pelo estudante em vias de ser professor como instrumentos ou estratégias de resistência e de fortalecimento. 
Notas

${ }^{1}$ Ver HYMES, Dell (1974) Foundations in Sociolinguistics. An Ethnographic Approach. Philadelphia, PA.: University of Pennsylvania Press; GUMPERZ, J. J. Discourse Strategies. Cambridge: Cambridge University Press, 1982. Também para o dialogismo, a interação é fundamental na vida social. (VOLOSHINOV, V.N. ([1929]1986). Marxism and the Philosophy of Language. Harvard, Mass. Cambridge University Press.)

${ }^{2}$ Prolongando a metáfora do tecido, trama em duas cores diferentes: a da ação social e a da ação acadêmica sobre os conteúdos que se está querendo ensinar (cf. ERICKSON, F. (1982) "Classroom Discourse as Improvisation: Relationships between Academic Task Structure and Social Participation Structure in Lessons”. In L. C. Wilkinson (Org.) Communicating in the Classroom. N.Y. Academic Press.

${ }^{3}$ HÉBRARD, Jean. "Três figuras de jovens leitores: alfabetização e escolarização do ponto de vista da história cultural”. In: Abreu, Márcia (Org.) Leitura, História e História da Leitura. Campinas: Mercado de Letras; Associação de Leitura do Brasil: São Paulo: Fapesp, 2000, p. 37.

${ }^{4}$ Embora seja claro que todo professor deveria promover a leitura dos textos de sua especialidade, essa função é (erroneamente) atribuída quase que exclusivamente ao professor de Língua Portuguesa.

${ }^{5}$ Projeto Temático Formação do professor: processos de retextualização e práticas de letramento, financiado pela FAPESP (Processo 02/09775-0). As reflexões aqui apresentadas foram desenvolvidas no âmbito desse projeto.

${ }^{6}$ Do Grupo Letramento do Professor, coordenado pela autora, participam as professoras doutoras Ana Lúcia Guedes Pinto, da Faculdade de Educação da Unicamp; Maria de Lourdes Matencio, Jane Q. da Silva e Juliana Assis da PUCMinas; Vera Masagão Ribeiro, da Ação Educativa. Desde 2006, outros pesquisadores têm sido integrados à equipe do projeto: os professores doutores Cosme dos Santos, da Universidade Estadual de Bahia; Eveline Tápias Oliveira da Universidade de Taubaté, Simone Borges da Silva, da Universidade Federal de Santa Catarina, Maria Silvia Cintra Martins, da Universidade Federal de São Carlos e Maria do Socorro Oliveira, da Universidade Federal do Rio Grande do Norte. Do projeto já resultaram sete doutorados e quatorze mestrados e há outros nove doutorados e quatorze mestrados em curso.

${ }^{7}$ A investigação diz respeito aos usos da escrita, mas aqui focalizaremos apenas a leitura.

${ }^{8}$ KLEIMAN, Angela B. (2006b) "Professores e agentes de letramento: identidade e posicionamento social", Revista Filologia e Lingüistica Portuguesa, nº 08.

${ }^{9}$ Em geral o alvo dessas críticas é a professora alfabetizadora (praticamente todas mulheres), até há pouco sem diploma universitário, mas também o professor de português é assim representado.

${ }^{10}$ Aspecto contestado por diversos pesquisadores do grupo, a partir de diversas perspectivas. Ver KLEIMAN, Angela B. (2001) 'Letramento e formação do professor: quais as práticas e exigências do trabalho?’' In: KLEIMAN, A. B. (Org.). A formação do professor:perspectivas da Lingüística Aplicada. Campinas: Mercado de Letras; BORGES DA SILVA, Simone B. (2003) Formação de Professores e PCN: um olhar sobre a leitura e o material de leitura. Tese de Doutorado, Campinas: Unicamp.

${ }^{11}$ A capacidade de ler um pequeno texto em prosa foi avaliada por Ribeiro num estudo abrangente sobre o letramento de diversos segmentos sociais na cidade de São Paulo. A categoria que incluía professores e profissionais liberais obteve alta pontuação nesse item em 58\% dos casos. RIBEIRO, V. M. (1999) Alfabetismo e atitudes. Campinas: Papirus; São Paulo: Ação Educativa.

${ }^{12}$ CASTRO, Rosana L. de. (2007) Concepsões e práticas de leitura de formando em Letras. Dissertação de Mestrado, São Paulo: USP.

${ }^{13}$ ARCHER, Margaret S. (2000). Being Human: The Problem of Agency. Cambridge: Cambridge University Press. ${ }^{14}$ KLEIMAN, Angela B. (2006a) "Processos identitários na formação profissional: o professor como agente de letramento”, In: CORRÊA, Manoel \& BOCH, F. (Orgs.). Ensino de Lingua: representação e letramento. Campinas: Mercado de Letras.

${ }^{15}$ VÓVIO, Claudia L. (2007) Entre discursos. Representações, práticas e identidades leitoras de alfabetizadoras de pessoas jovens e adultas. Tese de doutorado. Campinas: Unicamp.

${ }^{16}$ GARCIA CANCLINI, N. (1989) Culturas Hibridas. Estrategias para entrary salir de la modernidad. Mexico, D.F.: Editorial Grijalbo.

${ }^{17}$ Os grupos da PUC-Minas e da Universidade de Taubaté reelaboram seus currículos e programas de disciplinas (respectivamente) com base nos resultados do projeto. 
${ }^{18}$ Ver, por exemplo, KLEIMAN, Angela B. (2001) "Letramento e formação do professor: quais as práticas e exigências do trabalho?” In: KLEIMAN, A. B. (Org.). A formação do professor:perspectivas da Lingüistica Aplicada. Campinas: Mercado de Letras; BORGES DA SILVA, Simone B. (2003) Formação de Professores e PCN: um olhar sobre a leitura e o material de leitura. Tese de Doutorado, Campinas: Unicamp.

${ }^{19}$ VÓVIO, Claudia L. (2007) Entre discursos. Representações, práticas e identidades leitoras de alfabetizadoras de pessoas jovens e adultas. Tese de doutorado. Campinas: Unicamp.

${ }^{20}$ Cf. também VOVIO, Claudia Lemos \& SOUZA, Ana Lúcia Silva. (2005) "Desafios metodológicos em pesquisas sobre letramento". In: KLEIMAN, Angela B. \& MATENCIO, Maria de Lourdes M. (Orgs.). Letramento e formação do professor. Práticas discursivas, representações e construção do saber. Campinas: Mercado de Letras; SOUZA, Ana Lúcia S. (2007) "Letramento e identidade: um estudo sobre o discurso de jovens agentes de letramento no movimento hip-hop". In: CORRÊA, Manoel L. G. (Org.) Anais do II Simpósio Internacional sobre práticas escritas na escola: letramento e representação. São Paulo: USP, 2006. CD ROM.

${ }^{21}$ KLEIMAN, Angela B. (2006a) "Processos identitários na formação profissional: o professor como agente de letramento", In: CORREAA, Manoel \& BOCH, F. (Orgs.). Ensino de Lingua: representação e letramento. Campinas: Mercado de Letras.

${ }^{22}$ DOS SANTOS, C. B. (2003). "A construção do conceito de coerência textual por professores em formação", Trabalhos em Lingüistica Aplicada, Campinas: Unicamp, no 41, p. 91-103; DOS SANTOS, C. (2005) Um Assunto Puxa o Outro: A Representação da Coerência Textual na Formaşão do Alfabetizador. Tese de Doutorado. Campinas: Unicamp. DOS SANTOS, Cosme B. (2006) "Ensinar não é empurrar o conteúdo de goela abaixo": a construção da definição de pedagogia progressista pelo alfabetizador em formação. In. Trabalhos em Linguïstica Aplicada, $\mathrm{n}^{\circ}$ 45, p. 135-145. MAGALHÃES, Luciane M. (2005) Representações Sociais da Leitura. Práticas Discursivas do Professor em Formaşão. Tese de Doutorado. Campinas: Unicamp.

${ }^{23}$ GEE, J. (1990). Social Linguistics and Literacies. Ideologies in discourses. Hampshire: The Falmer Press.

${ }^{24}$ MOSCOVICI, S. (1990). "Prefácio", In: GUARESCHI, P. e JOVCHELOVITCH, S. (Orgs.). Textos em representacões sociais. Petrópolis, Vozes.

${ }^{25}$ DOS SANTOS, C. (2005) Um Assunto Puxa o Outro: A Representação da Coerência Textual na Formação do Alfabetizador. Tese de Doutorado. Campinas: Unicamp; MATENCIO, Maria de Lourdes M. (2006) "Letramento na formação do professor - integração a práticas discursivas acadêmicas e construção da identidade profissional". In: CORREA, Manoel Luiz Gonçalves \& BOCH, Françoise (Org.). Ensino de lingua: representação e letramento. Campinas: Mercado de Letras.

${ }^{26}$ KLEIMAN, Angela B. (2005) "As metáforas conceituais na educação lingüística do professor: índices da transformação de representações e saberes na interação". In: KLEIMAN, A. B. \& MATENCIO, M. L. M. Letramento e formação do professor: práticas discursivas, representações e construção do saber. Campinas: Mercado de Letras, p. 203-228.

${ }^{27}$ Segundo Marcuschi, que analisa a atividade na passagem da fala para a escrita, retextualizar é transformar um texto em outro. (MARCUSCHI, L.A. (2000) Da fala para a escrita. Atividades de retextualização. São Paulo: Cortez Editora.)

${ }^{28}$ MATENCIO, M. L. M. (2002). "Atividades de (re)textualização em práticas acadêmicas: um estudo do resumo", Revista Scripta, v. 6, n 11. Belo Horizonte, p. 109-122. SILVA, Jane Q. G. \& MATENCIO, Maria de Lourdes M. (2004) "Movimentos do sujeito na produção de sentidos: subjetivação e objetivação". Revista Scripta, $\mathrm{n}^{\circ}$ 15, $2^{\circ}$ sem. Belo Horizonte: PUC-Minas. MATENCIO, Maria de Lourdes M. \& SILVA, Jane Q. G. (2005) "Movimentos do sujeito na produção de sentidos: subjetivação e objetivação". Revista Scripta, n. 16, $1^{\circ}$ sem., Belo Horizonte.

${ }^{29}$ MATENCIO, Maria de Lourdes M. (2006) "Letramento na formação do professor - integração a práticas discursivas acadêmicas e construção da identidade profissional". In: CORREA, Manoel Luiz Gonçalves \& BOCH, Françoise (Org.). Ensino de língua: representação e letramento. Campinas: Mercado de Letras.

${ }^{30}$ BUNZEN, C. (2006). "Reapresentação de objetos de ensino em livros didáticos de língua portuguesa: um estudo exploratório". In: SIGNORINI, I. (Org.) Significados da inovação no ensino de Lingua Portuguesa e na formação de professores. Campinas: Mercado de Letras.

${ }^{31}$ GUEDES-PINTO, A. L. (2004) "Oral History under an interdisciplinary perspective: a report on an experience in Brazil". In: XIII International Oral History Conference-Memory and Globalization, 2004, Roma, Itália, v. 1. p. 1-8. GUEDES-PINTO, A. L. (2005) "Fragmentos de historias de lectura y escritura de profesoras-alfabetizadoras en 
la ciudad de Campinas, São Paulo, Brasil, en la contemporaneidad del siglo XX”. In: PENHA, María del Val González de la (Org.). Mujer y cultura escrita - del mito al siglo XXI. Gijón (Asturias), Espanha, p. 251-266. GUEDES-PINTO, A. L.; GOMES, Geisa G.; SILVA, Leila C. B. (2005) "Percursos de letramento dos professores: narrativas em foco". In: KLEIMAN, A. B. \& MATENCIO, M. L. M. Letramento e formação do professor: práticas discursivas, representaçoes e construção do saber. Campinas: Mercado de Letras, p. 65-92.

${ }^{32}$ PORTELLI, Alessandro (1997) "Tentando aprender um pouquinho. Algumas reflexões sobre a ética na História Oral”. Projeto História, São Paulo, SP: Abril, nº 15.

${ }^{33}$ CORRÊA, Julia A. M. (em andamento). A professora leitora na Amazônia: memória, identidade e travessias. Tese de Doutorado, Campinas: Unicamp.

${ }^{34}$ TÁPIAS-OLIVEIRA, Eveline M. (2005) "A construção da identidade profissional do professor e sua produção diarista" In: KLEIMAN, Angela B; MATENCIO, Maria de Lourdes M. (Orgs.) Letramento e formação do professor: práticas discursivas, representacões e construção do saber. São Paulo: Mercado de Letras; DIAS, Carolina Assis. (2004) "O aprendizado do professor em formação através da prática em sala de aula". In: Seminário de Pesquisas da Graduação $1^{\circ}$ SePeG. Campinas: Editora da Unicamp, v. 1. p. 109-114.

${ }^{35}$ TINOCO, Glícia Azevedo (em andamento) Projetos de letramento:princípiospara a ressignificaşão do ensino da escrita em lingua materna, Tese de Doutorado, Campinas: Unicamp.

${ }^{36}$ A noção de comunidade de aprendizagem tem sido utilizada por Afonso, para se referir a um grupo que age colaborativamente para a construção do conhecimento e para a consecução de objetivos e metas preestabelecidos pelo grupo. Achamos importante frisar que, na nossa concepção, essas comunidades são formadas para resolver uma questão de interesse de todos e, conseqüentemente, são renováveis, fluidas e provisórias. AFONSO, Ana Paula. (2001) "Comunidades de aprendizagem: um modelo para a gestão da aprendizagem". In: II Conferência Internacional Challenges 2001, pág. 427-432. http://www.nonio.uminho.pt/challenges/actchal01/ 048 Ana $\% 20$ Afonso $\% 432$.

${ }^{37}$ KLEIMAN, Angela B. (2000) "O processo de aculturação pela escrita: ensino de forma ou aprendizagem da função?” In: KLEIMAN, A. B. \& SIGNORINI, I. O ensino e a formação do professor: alfabetizaçãao de jovens e adultos. Porto Alegre: Artes Médicas.

${ }^{38}$ TINOCO, Glícia Azevedo (em andamento) Projetos de letramento:princípios para a ressignificaşão do ensino da escrita em língua materna, Tese de Doutorado, Campinas: Unicamp.

${ }^{39}$ FARINHA, G. S. (2004) Era uma vez um grupo de professoras.... Análise de uma história de letramento e de formação continuada. Dissertação de Mestrado, Campinas: Unicamp.

${ }^{40}$ MATENCIO, Maria de Lourdes M. (a sair) "Gêneros discursivos na formação de professores: reflexões sobre a construção de saberes e o processo de letramento”. In: GIL, Gloria \& ABRAHÃO, Maria Helena Vieira (Orgs.). A formacão do professor de linguas: os desafios do formador. Florianópolis: UFSC; ASSIS, Juliana Alves \& MATA, M. A. (2005) "A escrita de resumos na formação inicial do professor de Língua Portuguesa: movimento de aprendizagem no espaço da sala de aula". In KLEIMAN, A. B. \& MATENCIO, M. L. M. Letramento e formacão do professor: práticas discursivas, representações e construção do saber. Campinas: Mercado de Letras, p. 181-202. 


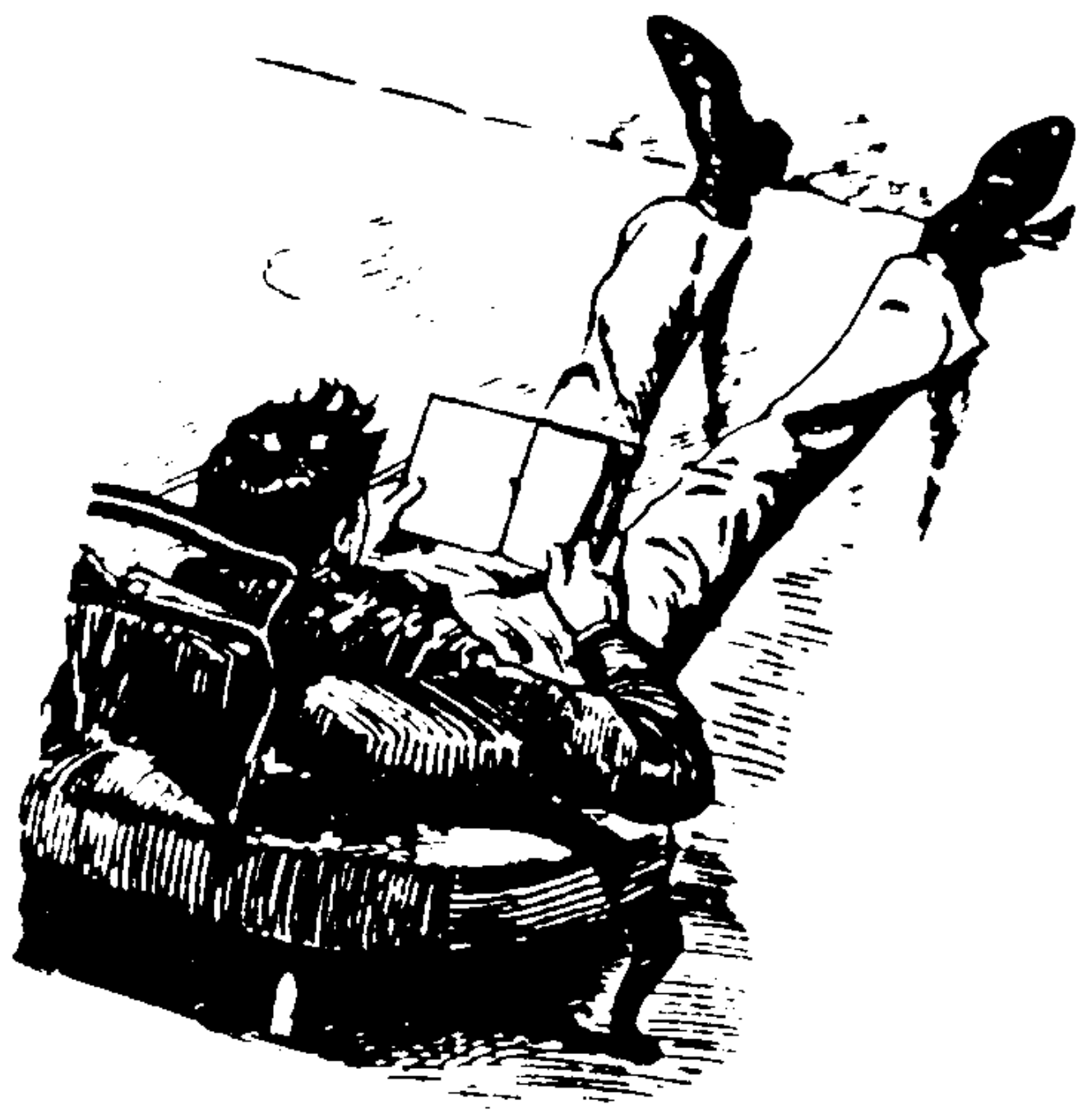

